NASZA DERMATOLOGIA Online OUR DERMATOLOGY Online

Source of Support:

Nil

Competing Interests:

None declared

\section{EPONYMS IN MEDICAL LITERATURE LINKED TO NURSES}

\author{
Daifullah Al Aboud
}

Dermatology Department, Taif University, Taif, Saudi Arabia

Corresponding author: Dr. Daifullah Al Aboud

dalaboud@hotmail.com
Nursing is one of the oldest professions in the human life. It is a profession within the healthcare sector focused on the care of individuals.

An eponym is a word derived from the name of a person. Most of the eponyms in medicine are after physicians and rarely to other healthcare providers like nurses.

In Table I [1-8], I highlighted on two famous medical eponyms that are linked to nurses. The association with the name of a nurse represents beyond doubt a special feature and reflects the great contributions, these nurses made.

There is no wonder that both eponyms are for females, as it is around the world, nurses have been traditionally female. And despite equal opportunity legislation, nursing has continued to be a female-dominated profession.

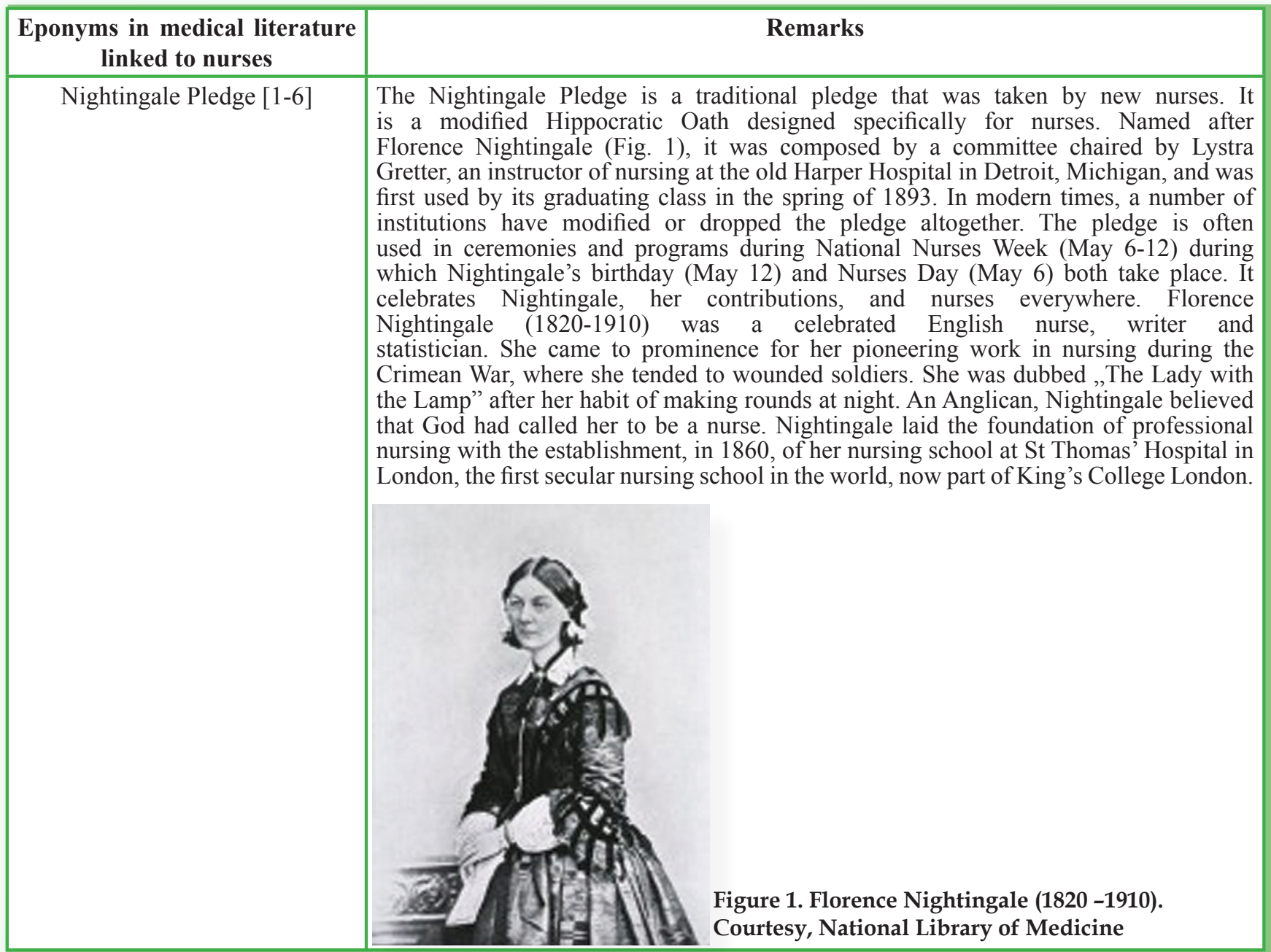




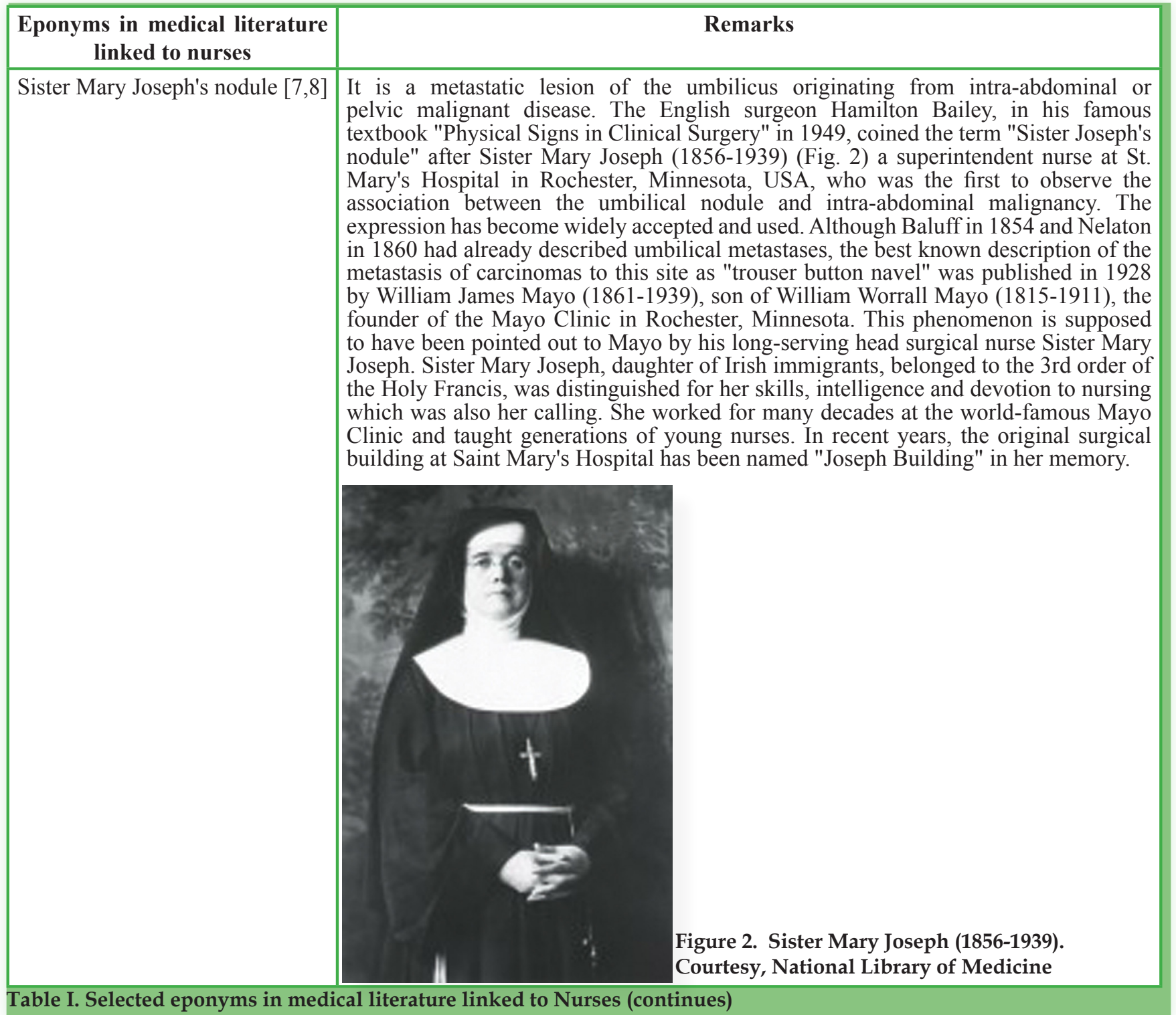

\section{REFERENCES}

1. Nightingale P: Wikipedia ${ }^{\circledR}$ [Internet]. Wikimedia Foundation. [Updated 14 May 2012; cited 30 June 2012]. Available from: http:// en.wikipedia.org/wiki/Nightingale_Pledge

2. Vieira M: [The Nightingale Pledge, today]. Servir. 2008;56:97-8. 3. Miracle VA: National nurses' week and the Nightingale pledge. Dimens Crit Care Nurs. 2009;28:145-6.

4. Nightingale F: Florence Nightingale. Wikipedia ${ }^{\circledR}$ [Internet]. Wikimedia Foundation. [Updated 30 June 2012; cited 30 June 2012]. Available from: http://en.wikipedia.org/wiki/Florence Nightingale
5. Nightingale F: Cassandra: an essay. 1979. Am J Public Health. 2010;100:1586-7.

6. Garofalo ME, Fee E: Florence Nightingale (1820-1910): feminism and hospital reform. 2010. Am J Public Health. 2010;100:1588.

7. Trebing D, Göring HD: [The umbilical metastasis. Sister Mary Joseph and her time]. Hautarzt. 2004;55:186-9.

8. Abu-Hilal M, Newman JS: Sister Mary Joseph and her nodule: historical and clinical perspective. Am J Med Sci. 2009;337:271-3.

Copyright by Daifullah Al Aboud. This is an open access article distributed under the terms of the Creative Commons Attribution License, which permits unrestricted use, distribution, and reproduction in any medium, provided the original author and source are credited. 